\title{
Proceeding
}

Supplementary Issue: Spring Conferences of Sports Science. Costa Blanca Sports Science Week, 26-28 April 2018. Calpe. Alicante, Spain

\section{Effects of a 12-week-long program of vigorous- intensity physical activity on the body composition of 6-and 7-year-old children}

\author{
GUILLERMO FELIPE LÓPEZ SÁNCHEZ1 $₫$, FRANCISCO JOSÉ BORREGO BALSALOBRE , ARTURO \\ DÍAZ-SUÁREZ1', LEE SMITH² \\ ${ }^{1}$ Faculty of Sports Sciences, University of Murcia, Spain \\ ${ }^{2}$ Cambridge Centre for Sport and Exercise Science, Anglia Ruskin University, United Kingdom
}

\begin{abstract}
The purpose was to study the effects of a program of vigorous-intensity physical activity (PA) on the body composition of children. This investigation involved 32 school children from 6 to 7 years old (14 males 6.57 \pm 0.51 yr., and 18 females $6.33 \pm 0.49$ yr.). The variables measured were: body weight, fat-free mass (FFM), fat mass (FM), total body water (TBW), basal metabolic rate (BMR), body mass index (BMI), fat-free mass index (FFMI) and fat mass index (FMI). The body composition analysis was performed using bioelectrical impedance through the body fat monitor Tanita BC 418-MA Segmental. Stadiometer HM - 250P Leicester was also used to obtain the height. The procedure was as follows: pre-test, intervention and post-test. The intervention consisted of 3 days per week of vigorous-intensity physical activity, 15 minutes per day, during 12 weeks. Data analysis was performed through SPSS 23 and significant improvements $($ Sig $<0.05)$ were obtained in all the variables except for BMI. The physical activity program used in this study may be useful to improve body composition in 6-and 7-year-old children. Key words: BMI, FAT MASS, HEALTH, PHYSICAL EDUCATION, SCHOOL CHILDREN.
\end{abstract}

Cite this article as:

López Sánchez, G., Borrego Balsalobre, F., Díaz-Suárez, A., \& Smith, L. (2018). Effects of a 12-weeklong program of vigorous-intensity physical activity on the body composition of 6-and 7-year-old children. Journal of Human Sport and Exercise, 13(2proc), S445-S453. doi:https://doi.org/10.14198/ihse.2018.13.Proc2.28

Corresponding author. Facultad de Ciencias del Deporte (Campus de San Javier, Universidad de Murcia). C/Argentina s/n. 30720 - Santiago de la Ribera-San Javier (Murcia), Spain. http://orcid.org/0000-0002-9897-5273

E-mail: gfls@um.es

Supplementary Issue: Spring Conferences of Sports Science. Costa Blanca Sports Science Week, 26-28 April 2018. Calpe. Alicante, Spain.

JOURNAL OF HUMAN SPORT \& EXERCISE ISSN 1988-5202

(c) Faculty of Education. University of Alicante

doi: 10.14198/jhse.2018.13.Proc2.28 


\section{INTRODUCTION}

Body composition $(\mathrm{BC})$ can be understood as the division of body weight in different compartments that constitute the human body (Berral et al., 1991). Therefore, BC analysis allows to know the proportions of the various constituents' parts of the human body (Moreno, 2000). According to Moreno (2000), the model traditionally used to evaluate $\mathrm{BC}$ is the model of two compartments, or bicompartmental, which posits that the human body is composed of a part of fat mass and another part of fat-free mass; or alternatively, fat mass and lean mass.

$\mathrm{BC}$ is closely related to people's health and measurement of $\mathrm{BC}$ allows the early detection of certain diseases (López et al., 2015a). As Cordova et al. (2013) noted, there is an increased prevalence of obesity during childhood, which can also lead to chronic diseases related to inactivity and obesity in adulthood. Currently childhood obesity is one of the major concerns regarding long-term health (Duncan et al., 2006).

Consequently, any action aimed at improving body composition in the population is justified, as it entails simultaneously improved health and reduction of the possibility of disease. Physical activity is proposed as the ideal means to improve physical fitness and body composition in children and adolescents, according to numerous studies (Borrego et al., 2015 a, b; López et al. 2013, 2015a; Ortega et al., 2013; Plonka et al. 2011). Physical activity can also be beneficial for the body composition of people with special needs, such as schoolchildren with ADHD (López et al. 2015b).

However, recent research indicates that schoolchildren are not doing enough physical activity during the day (Pérez et al., 2011), because nowadays in society the need to move and make any kind of physical effort is ever decreasing, and there are numerous behaviors that involve being seated for a long time throughout the day (Pate et al., 2011).

Overall, there is consensus on the need to increase levels of physical activity, since, according to different studies, regular physical exercise has a significant effect on weight loss due to important changes in circulation, hormonal status, the nervous system, the transport of substrates and the mobilization of lipids (Aguilar et al. 2014).

In this sense, Pienaar et al. (2013) concluded that the profile of body composition and physical fitness of children can improve with a multidisciplinary program that includes behavioral changes regarding physical activity and diet, although it should be in a continuous and controlled manner.

Likewise, high levels of physical activity, practiced regularly, can provide protection against obesity in children and adolescents (Herman et al., 2014). Besides, as shown in the study of Palencia et al. (2015), a higher number of minutes of vigorous physical activity is associated with indicators of lower adiposity and better physical fitness in schoolchildren aged 9 and 10 , while less time is related to low cardiorespiratory physical fitness and an increased likelihood of being overweight and obese.

Nevertheless, it is necessary to take into account the intensity factor, since it is possible that a certain threshold of intensity may influence to a greater or lesser extent individual body composition (Abbott and Davies, 2004). Several studies have found significant relationships between physical activity (especially vigorous) and healthy body composition (Riddoch et al. 2009). In the same vein, Cho and Koh (2014) suggest that an aerobic exercise program coupled with dietary changes is effective for children who are overweight or obese and could have positive effects on body composition and healthy physical fitness. 
Due to the direct relationship of body composition with an individual's state of health, more intervention programs are needed to improve people's body composition and, consequently, their health. The main objective of this research is to determine the effectiveness of a 12-week program of vigorous-intensity physical activity on the body composition of 6-and 7-year-old schoolchildren. The study assumes that the program of vigorous-intensity exercises reduces fat mass and improves other parameters of body composition in children.

\section{MATERIAL AND METHODS}

\section{Participants}

32 school children from 6 to 7 years old participated in the study (14 males: $6.57 \pm 0.51$ yr.; and 18 females: $6.33 \pm 0.49 \mathrm{yr}$.). The children are in primary school and they have two hours of PE per week, but they do not practice any kind of sports outside the school. The research was approved by the Research Ethics Committee of the University of Murcia and all the students and their parents/legal guardians gave informed consent. The work has been carried out in accordance with The Code of Ethics of the World Medical Association (Declaration of Helsinki) for experiments involving humans.

\section{Design}

This study had a pre-post quasi-experimental design with a single intervention group, since the students were selected for their interest in the proposed physical activity program, in a non-randomized manner, and it was considered as a primary aspect of the research that all the students could participate in the physical activity program. The subjects participating in the study performed a pre-test, a 12-week intervention program and a post-test.

The program consisted of 3 sessions per week of vigorous-intensity physical activity and the duration of each lesson was 15 minutes. The teachers of the school children were the same along the whole program and the lessons were conducted according to the predetermined program. The duration of the experiment was 12 weeks. Body composition was measured at the beginning and at the end of the experiment. PA lessons were carried out outdoors from January to April, with an average ambient temperature of $15^{\circ} \mathrm{C}$, an average humidity level of $70 \%$ and an average atmospheric pressure of $1000 \mathrm{hPa}$.

\section{PA program}

The intensity of the activity of the experimental group was vigorous, always taking into account that the target group was composed of children, and in order to motivate them it was necessary to disguise the activities by means of games avoiding the analytical and traditional. To accomplish this, a set of games was developed to avoid monotony, which included the following: relay races, sprints, running, skipping rope and competitive sports and games.

All the games were set up in adapted spaces and with the necessary rules to achieve vigorous-intensity physical activity. In this manner vigorous intensity intervallic participation was achieved. If the intensity of the game seemed to decrease, a new incentive was quickly put into place, a small rule or modification or sometimes the researchers even took part in the game in order to maintain the intensity of the session.

\section{Body Composition measurements}

All participants were measured for selected body mass and body composition variables before and after the completion of the 12-week period. Measurements were performed in the morning, more than three hours after waking up and after last eating and drinking. Body mass and body composition were assessed with the 
bioelectrical impedance method (body's inherent resistance to an electrical current) using a Tanita BC 418MA body composition analyzer (Tanita, Tokyo, Japan). All the recommendations for the analysis of bioelectrical impedance were followed. The device was plugged in and calibrated to account for the weight of clothing $(0.2 \mathrm{~kg})$. Afterwards, data regarding age, sex and body height of the subject were entered. Stadiometer HM - 250P Leicester (Marsden Scales, Rotherham, United Kingdom) was used to measure the height. Then, the subjects stood on the scale with their bare feet and hands on the marked places. The device analyzes body composition based on the differences of the ability to conduct electrical current by body tissues (different resistance) due to different water content. The variables measured were: body weight $(\mathrm{kg})$, fat-free mass (FFM, $\mathrm{kg}$ and \%), fat mass (FM, $\mathrm{kg}$ and \%), total body water (TBW, $\mathrm{kg}$ and \%), and basal metabolic rate (BMR, kcal). Additionally, the next indexes were calculated: body mass index (BMl, $\left.\mathrm{kg} / \mathrm{m}^{2}\right)$, fat-free mass index (FFMl, $\left.\mathrm{kg} / \mathrm{m}^{2}\right)$ and fat mass index $\left(\mathrm{FMl}, \mathrm{kg} / \mathrm{m}^{2}\right)$.

\section{Statistical analysis}

Data analysis was performed using Statistical Package for Social Sciences 23 (SPSS-23). The Shapiro-Wilk test was used to estimate the normality of the sample. Paired Samples $t$ Test was used to know if there were significant differences between the pre-test and the post-test. This test was applied on the total sample and also segmenting by sex and age. Each time, $P<0.05$ was considered as a significant difference $\left(^{*}\right)$.

\section{RESULTS}

Results are presented in the following two tables, comparing the pre-post differences in males and females. Significant improvements $($ Sig<0.05) were obtained in all the variables except for BMI.

Table 1. Pre-post differences in females $(\mathrm{N}=18)$

\begin{tabular}{|c|c|c|c|c|c|c|}
\hline & \multirow[t]{2}{*}{ Pretest } & \multirow[t]{2}{*}{ Postest } & \multicolumn{4}{|c|}{ Paired Sample T-Test } \\
\hline & & & MDif. & $t$ & $\mathrm{df}$ & Sig. \\
\hline Body Weight (kg) & $25,71 \pm 5,47$ & $26,79 \pm 5,92$ & 1,08 & 5,312 & 17 &, $000^{*}$ \\
\hline $\mathrm{BMI}\left(\mathrm{kg} / \mathrm{m}^{2}\right)$ & $17,58 \pm 2,81$ & $17,45 \pm 2,89$ & 12 &, 611 & 17 &, 550 \\
\hline FFM (kg) & $18,71 \pm 2,89$ & $20,23 \pm 3,33$ & 1,52 & 9,877 & 17 &, $000^{*}$ \\
\hline FFM $(\%)$ & $73,52 \pm 4,68$ & $76,26 \pm 4,41$ & 2,74 & 4,518 & 17 &, $000^{*}$ \\
\hline FFMI $\left(\mathrm{kg} / \mathrm{m}^{2}\right)$ & $12,81 \pm 1,30$ & $13,19 \pm 1,36$ & ,38 & 3,053 & 17 &, $007^{*}$ \\
\hline $\mathrm{FM}(\mathrm{kg})$ & $7,00 \pm 2,76$ & $6,57 \pm 2,75$ & ,43 & 2,460 & 17 &, $025^{*}$ \\
\hline $\mathrm{FM}(\%)$ & $26,48 \pm 4,68$ & $23,74 \pm 4,41$ & 2,73 & 4,518 & 17 &, $000^{*}$ \\
\hline $\mathrm{FMI}\left(\mathrm{kg} / \mathrm{m}^{2}\right)$ & $4,76 \pm 1,61$ & $4,26 \pm 1,56$ &, 50 & 3,851 & 17 &, $001^{*}$ \\
\hline TBW $(\mathrm{kg})$ & $13,69 \pm 2,11$ & $14,82 \pm 2,42$ & 1,13 & 10,253 & 17 &, $000^{*}$ \\
\hline TBW $(\%)$ & $53,83 \pm 3,43$ & $55,92 \pm 3,31$ & 2,08 & 4,652 & 17 &, $000^{*}$ \\
\hline BMR (kcal) & $1000,89 \pm 79,14$ & $1025,22 \pm 89,02$ & 24,33 & 6,742 & 17 &, $000^{*}$ \\
\hline
\end{tabular}


Table 2. Pre-post differences in males $(\mathrm{N}=14)$

\begin{tabular}{|c|c|c|c|c|c|c|}
\hline & \multirow[t]{2}{*}{ Pretest } & \multirow[t]{2}{*}{ Postest } & \multicolumn{4}{|c|}{ Paired Sample T-Test } \\
\hline & & & MDif. & $t$ & $\mathrm{df}$ & Sig. \\
\hline Body Weight (kg) & $27,31 \pm 5,61$ & $28,40 \pm 6,16$ & 1,09 & 3,780 & 13 &, $002 *$ \\
\hline BMI $\left(\mathrm{kg} / \mathrm{m}^{2}\right)$ & $17,13 \pm 2,63$ & $17,11 \pm 2,79$ &, 01 &, 089 & 13 &, 931 \\
\hline FFM $(\mathrm{kg})$ & $20,9 \pm 3,82$ & $22,25 \pm 4,15$ & 1,33 & 7,704 & 13 &, $000^{*}$ \\
\hline FFM $(\%)$ & $77,02 \pm 4,14$ & $78,86 \pm 3,92$ & 1,83 & 4,312 & 13 &, $001^{*}$ \\
\hline FFMI $\left(\mathrm{kg} / \mathrm{m}^{2}\right)$ & $13,13 \pm 1,62$ & $13,42 \pm 1,71$ & ,29 & 2,627 & 13 &, $021^{*}$ \\
\hline $\mathrm{FM}(\mathrm{kg})$ & $6,39 \pm 2,21$ & $6,15 \pm 2,30$ & ,24 & 1,388 & 13 & ,188 \\
\hline $\mathrm{FM}(\%)$ & $22,98 \pm 4,15$ & $21,14 \pm 3,92$ & 1,83 & 4,312 & 13 &, $001^{*}$ \\
\hline FMI $\left(\mathrm{kg} / \mathrm{m}^{2}\right)$ & $4,01 \pm 1,27$ & $3,69 \pm 1,26$ & ,31 & 2,891 & 13 &, $013^{*}$ \\
\hline TBW (kg) & $15,31 \pm 2,78$ & $16,30 \pm 3,05$ & ,99 & 7,303 & 13 &, $000^{*}$ \\
\hline TBW $(\%)$ & $56,39 \pm 3,09$ & $57,76 \pm 2,83$ & 1,37 & 4,637 & 13 &, $000^{*}$ \\
\hline BMR (kcal) & $1149,86 \pm 90,82$ & $1179,43 \pm 100,19$ & 29,57 & 6,757 & 13 &, $000^{*}$ \\
\hline
\end{tabular}

\section{DISCUSSION}

The results of our research indicated that in the both males and females there were significant improvements $($ Sig<0.05) in all the variables of body composition except for BMI.

Piennar et al. (2013) studied the effect of a physical activity, diet, and behavior modification intervention of 13 weeks, three times per week for 60 minutes on the body composition of 37 overweight and obese children with a mean age of 11 years (20 subjects in the intervention group and 17 in the control group). They studied the variables body weight, BMI and FM \%. In Piennar et al. study, body weight increased significantly in CG $(2.25 \mathrm{~kg})$ and decreased significantly in $\mathrm{EG}(-2.82 \mathrm{~kg})$; in the present study body weight increased significantly in males and females. In the study of Piennar et al., BMI increased significantly in CG (0.6) and decreased significantly in EG (-1.9); in this study BMI practically did not change. In Piennar et al. study, FM increased in CG $(3.8 \%)$ and decreased in EG (-4.34\%); in the present study males and females reduced significantly FM.

Similarly, Aguilar et al. (2014), in their systematic review on physical activity programs to reduce excess weight and obesity in children and adolescents, indicated that several studies found links between physical activity and improvements in fat-free mass and BMI. Likewise, López et al. (2015) implemented a program of physical activity of 12 weeks (2 hours per week) in a sample of 12 male schoolchildren with ADHD, with an average age of 9.38 years old. The physical activity lessons were specially prepared for ADHD children. The authors found an increase in the body weight $(0.6 \mathrm{~kg})$, like in the present research, where males and females of both groups increased their body weight too. The sample of López et al. saw a slight reduction in BMI (-0.21), but this difference was not significant; similarly in the present study BMI practically did not change. López et al. found a no significant reduction of FM $(-0.28 \%)$, while in the present study males (1.83\%) and females $(2.73 \%)$ significantly reduced this variable.

In the same vein, Cordova et al. (2013) studied a sample of 137 children aged 11 to 13 and found that the children who were more physically active had lower BMl and fat mass percentage, results consistent with the present study. Nevertheless, Arriscado et al. (2015) analyzed a sample of 329 schoolchildren (aged 11 and 12 years) and found no significant relation between physical activity and body composition, unlike in the present study. 
Plonka et al. (2011) studied 59 girls aged between 9 and 16 years (average $12.55 \pm 1.67 \mathrm{yr}$ ), divided in two groups: 29 physically active (PA) girls (regular swimming training on average $6.93 \pm 4.98$ month/year, $5 \pm 1.86$ days/week and $2.20 \pm 1.07$ hours/day) and 30 physically inactive (PI) girls (physically active on average for $6.94 \pm 4.15$ month/year, $1.69 \pm 1.09$ days/week and $1.11 \pm 0.46$ hours/day). In the study the BMI of PA girls $(18.19 \pm 2.29)$ was significantly lower than the BMI of PI girls $(20.57 \pm 4.33)$; in the present study the BMl practically did not change. FM of PA girls $(18.39 \pm 7.02 \%)$ was also significantly lower than in PI girls $(22.97 \pm 9.72 \%)$; similarly, in the present research the girls had significant improvements in this variable. Regarding FM (kg), Plonka's et al. (2011) PA girls had lower values $(9.22 \pm 4.97 \mathrm{~kg})$ than PI girls $(12.34 \pm 7.62$ $\mathrm{kg})$, although this difference was not significant; in the present study, girls significantly reduced their fat $(\mathrm{kg})$.

Abbott and Davies (2004) studied the level of habitual physical activity and physical activity intensity and their relationship to body composition in 475 - to 10.5-year-old (mean age 8.4 $0.9 \mathrm{yr}$ ) children, obtaining that vigorous activity and hard activity were significantly correlated to body fat percentage $(r=-0.44, p=0.004$ and $r=-0.39, p=0.014$ ), but not BMl. In addition these authors found that moderate intensity activity was not correlated with measures of body composition. The results of Abbott \& Davies (2004) are similar to those of the present study.

Cho and Koh (2014) studied the effects of aerobic exercise on the body composition of 28 obese male children in elementary school. The children were divided into two groups: exercise group $(n=14)$ and control group ( $n=14)$. The exercise group received dietary behavior education and performed an aerobic exercise program during 12 weeks and, after the program, the exercise group showed a significantly reduced BMl. However, in the present study significant improvements were not found in BMI. Perhaps the most important factor for reducing BMI in children is their daily diet, and physical exercise only contributes to this process.

Collings et al. (2015) examined the associations between sedentary time and adiposity in 504 adolescents (42\% boys) from schools in Cambridgeshire, UK, with a mean age $15.0 \pm 0.3$ years. They found that sedentary time was not associated with change in adiposity in either gender and concluded that sedentary time may not determine changes in adiposity from mid-to late adolescence. These results differ from the present study, where an improvement in the body composition of the schoolchildren was observed when physical activity increased.

However, De Moraes et al. (2015) examined the associations between physical activity and body composition in 485 Brazilian children and found that both moderate-to-vigorous and vigorous physical activity was negatively associated with body composition (BMl and body fat percentage) variables. Duncan et al. (2006) also found a link between physical activity and body fat in 1115 children from New Zealand (536 boys, 579 girls) aged 5-12 years, like has been observed in the present paper.

In the study by López et al. (2013), the authors implemented a physical activity program to 36 schoolchildren (20 males and 16 females), aged 3 to 5 . The program consisted of intense physical activity three days per week, 15 minutes per day, for 12 weeks. These authors found practically no change in BMI $(0.222)$, like in the present study. The sample of López et al. (2013) significantly reduced FM (-1.68\%), like in the present research.

Palencia et al. (2015) analyzed the relationship between daily minutes of vigorous physical activity and adiposity in 179 schoolchildren (97 girls) 9 to 10 years old. They found that vigorous physical activity is associated with lower adiposity. Specifically, they found that more than 14.5 daily minutes of vigorous physical activity was associated with lower adiposity indicators (the probability of excess weight and obesity 
increased 1.8 times if they had fewer minutes). In the present study, the results fall in line with the results of Palencia et al. (2015).

Finally, it is important to note some considerations. In this study BMI practically did not change; perhaps one of the reasons could be that the children were in growing process. However, FM decreased and FFM increased in both males and females, an aspect that could be related to the increase in BMR, and that could be a future line of research.

\section{CONCLUSIONS}

The 12-week PE program of vigorous-intensity physical activity used in this research has shown its effectiveness to improve the body composition of 6-and 7-year-old children, being effective in both males and females. Therefore, the implementation of this program in schools is highly recommended.

In addition, in further studies it would be advisable to carry out other intervention programs through physical activity, with larger samples and of a longer duration. It is also recommended to use different types of physical activity, always taking into account the intensity factor. Thus, there will be more resources available to improve body composition of schoolchildren through physical activity and the effectiveness of these resources will be known.

\section{CONFLICTS OF INTEREST}

The authors have no conflicts of interest relevant to this article.

\section{ACKNOWLEDGMENTS}

This work was supported by the Seneca Foundation-Agency for Science and Technology of the Region of Murcia (Spain).

\section{REFERENCES}

Abbott RA, Davies PSW. Habitual physical activity and physical activity intensity: their relation to body composition in 5.0-10.5-y-old children. Eur J Clin Nutr, 2004; 58(2): 285-291. https://doi.org/10.1038/si.ejcn.1601780

Aguilar MJ, Ortegón A, Mur N, Sánchez JC, García JJ, García I, Sánchez AM. Physical activity programmes to reduce overweight and obesity in children and adolescents; a systematic review. Nutr Hosp, 2014; 30(4): 727-740. https://doi.org/10.3305/nh.2014.30.4.7680

Arriscado D, Muros JJ, Zabala M, Dalmau JM. Physical activity habits in schoolchildren: influential factors and relationships with physical fitness. Nutr Hosp, 2015; 31(3): 1232-1239. https://doi.org/10.3305/nh.2015.31.3.8186

Berral FJ, Escribano A, Berral CJ, Delgado C, Lancho JL, De Rose E. Comparative corporal composition study on the Faulkner an Kerr methods in athletes. 13th International Congress on Biomechanics. Perth. Australia, 1991.

Borrego-Balsalobre FJ, López-Sánchez GF, Díaz-Suárez A. Effects of a vigorous physical activity program in the strength of primary schoolchildren. TRANCES: Revista de Transmisión del Conocimiento Educativo y de la Salud, 2015a; 7(3): 387-406. 
Borrego-Balsalobre FJ, López-Sánchez GF, Díaz-Suárez A. Effects of a vigorous physical activity program in the endurance of primary school children. ATHLOS: International Journal of Social Sciences of Physical Activity, Game and Sport, 2015b; 8: 31-46.

Cho KJ, Koh SM. The Effects of Aerobic Exercise on the Body Composition and Physical Activity Promotion System (PAPS) in Obese Children. Journal of the Korea Entertainment Industry Association, 2014; 8(2): 197-203. https://doi.org/10.21184/jkeia.2014.06.8.2.197

Collings PJ, Wijndaele K, Corder K, Westgate K, Ridgway CL, Sharp SJ, Ekelund U. Prospective associations between sedentary time, sleep duration and adiposity in adolescents. Sleep med, 2015; 16(6): 717-722. https://doi.org/10.1016/i.sleep.2015.02.532

Cordova A, Villa G, Sureda A, Rodríguez JA, Martínez R, Sánchez MP. Energy consumption, body composition and physical activity levels in 11-to13-year-old Spanish children. Ann Nutr Metab, 2013; 63(3): 223-228. https://doi.org/10.1159/000348673

De Moraes GL, Oliveira LC, Leandro T, Matsudo V, Barreira TV, Tudor-Locke C, Katzmarzyk P. Moderate-to-Vigorous Physical Activity and Sedentary Behavior: Independent Associations With Body Composition Variables in Brazilian Children. Pediatr. Exerc. Sci, 2015; 27(3): 380-389. https://doi.org/10.1123/pes.2014-0150

Duncan JS, Schofield G, Duncan EK. Pedometer-determined physical activity and body composition in New Zealand children. Med Sci Sports Exerc, 2006; 38(8): 1402-1409. https://doi.org/10.1249/01.mss.0000227535.36046.97

Herman KM, Sabiston CM, Mathieu ME, Tremblay A, Paradis G. Sedentary behavior in a cohort of 8- to 10-year-old children at elevated risk of obesity. Prev. Med, 2014; 60: 115-120. https://doi.org/10.1016/j.ypmed.2013.12.029

López-Sánchez GF, Borrego-Balsalobre FJ, Díaz-Suárez A. Effects of a physical activity program on body composition of school children of 3-5 years. SPORT TK: Revista Euroamericana de Ciencias del Deporte, 2013; 2(2): 41-44.

López-Sánchez GF, López-Sánchez L, Díaz-Suárez A. Body composition and heart rate variability: relations to age, sex, obesity and physical activity. SPORT TK: Revista Euroamericana de Ciencias del Deporte, 2015a; 4(2): 33-40.

López-Sánchez GF, López-Sánchez L, Díaz-Suárez A. Effects of a physical activity program on the body composition of schoolchildren with ADHD. KRONOS: Revista Científica de Actividad Física y Deporte, 2015b; 14(2): 1-9.

Moreno-Villares JM. Techniques of body composition analysis. XXIX Congreso Nacional Ordinario de Pediatría de la Asociación Española de Pediatría, 2000.

Ortega FB, Ruiz J, Castillo MJ. Physical activity, physical fitness, and overweight in children and adolescents: evidence from epidemiologic studies. Rev Endocrinol Nutr, 2013; 60(8): 458-469. https://doi.org/10.1016/i.endonu.2012.10.006

Palencia NMA, Martínez MS, Herráiz MMG, Arribas SA, García AG, Bueno CA. La actividad física vigorosa se relaciona con menor adiposidad y una condición física saludables en niños de 9-10 años. Rev Andaluza Med Deporte, 2015; 8(1): 38-38. https://doi.org/10.1016/j.ramd.2014.10.046

Pate RR, Mitchell JA, Byun W, Dowda M. Sedentary behaviour in youth. Br J Sports Med, 2011; 45: 906 913. https://doi.org/10.1136/bjsports-2011-090192

Pérez M, Pfeffer F, Rubio M, Melendez G. Association of physical activity in 9 and 10 years old Mexican children with their weight and body composition. FASEB J, 2011; 25(1): 781-786. https://doi.org/10.1096/fj.1530-6860

Pienaar AE, Du Toit D, Truter L. The effect of a multidisciplinary physical activity intervention on the body composition and physical fitness of obese children. J Sports Med Phys Fitness, 2013; 53(4): 415 427. 
Plonka M, Toton-Morys A, Adamski $\mathrm{P}$, et al. Association of the physical activity with leptin blood serum level, body mass indices and obesity in schoolgirls. J Physiol Pharmacol, 2011; 62(6): 647-656.

Riddoch CJ, Leary SD, Ness AR, Blair SN, Deere K, Mattocks C, et al. Prospective associations between objective measures of physical activity and fat mass in 12-14 year old children: The Avon Longitudinal Study of Parents And Children (ALSPAC). BMJ, 2009; 339: b4544. https://doi.org/10.1136/bmi.b4544 